ARTIGO

\title{
Remando ou guiando o barco? Modelos de governança para as políticas de Educação Superior no Brasil pós-1990
}

Janaina $\mathrm{Ma}{ }^{\mathrm{a}}$

Diego Mota Vieira ${ }^{b}$

\section{Resumo}

Este artigo tem como objetivo analisar o papel que os governos no Brasil têm desempenhado na condução de políticas de Educação Superior, tomando como referência uma tipologia que estabelece quatro modos de governança para a este tipo de Educação: o hierárquico, o procedimental, a condução a distância e a autogovernança. Além disso, considera três diferentes fases do Estado avaliador, para analisar o seu grau de autonomia frente aos organismos internacionais. Com base no referencial teórico adotado, conduz-se um estudo de caso do sistema de Educação Superior brasileiro, no período de 1995 a 2017, por meio de pesquisa documental e análise de conteúdo. Os resultados indicam que o modo de governança das políticas de Educação Superior no Brasil é, predominantemente, de condução a distância, com traços do modo hierárquico. Além disso, evidencia-se que o Estado mantém relativa autonomia frente aos organismos internacionais, dando sinais de aproximação com a Organização para a Cooperação e Desenvolvimento Econômico.

Palavras-chave: Educação Superior. Governança. Avaliação da qualidade.

\section{Introdução}

As reformas na Educação Superior (ES) são marcadas por tendências e desafios globais, como a necessidade de expansão e diversificação, a massificação e a orientação para o mercado, a demanda por mais qualidade e eficiência e pelo aumento da accountability (HONG, 2018; UNESCO, 2014). Este artigo tem como objetivo analisar o papel que os governos no Brasil têm desempenhado

\footnotetext{
a Universidade de Brasília, Brasília, DF, Brasil.

b Universidade de Brasília, Brasília, DF, Brasil. 
na condução das políticas de ES, considerando o modo de governança adotado e sua autonomia frente aos organismos internacionais.

Toma-se como referência a classificação feita por Capano (2011), propondo quatro modos de governança nas políticas de ES: o hierárquico, o procedimental, a condução a distância e a autogovernança. A proposta é interessante ao objetivo deste trabalho, pois parte da premissa de que o papel dos governos varia de acordo com o sistema de governança estruturado. Além disso, propõe-se uma discussão em torno da mudança na noção de Estado avaliador, tomando como referência a reflexão proposta por Afonso (2013). O autor argumenta que o papel do estado, em sua função avaliadora, tem mudado de uma fase em que há uma expressiva autonomia dos estados-nação na condução das políticas educacionais para uma fase em que há uma retração dessa autonomia em favor da atuação dos organismos internacionais (AFONSO, 2013).

A análise é concentrada num estudo de caso do sistema de ES brasileiro, que, além de ser o maior da América Latina, possui uma ampla participação do setor privado e um sistema nacional de avaliação da ES em vigor no país há 15 anos. O restante do texto está assim organizado: as seções 2 e 3 apresentam o referencial teórico e a metodologia utilizada. A seção 4 apresenta os resultados e as discussões e a seção final conclui com recomendações para pesquisas futuras.

\section{Modos de governança e ação governamental em sistemas de ES}

O papel dos governos tem sido um tema constante no debate sobre governança. $\mathrm{Na}$ administração pública, a noção de governança está comumente ligada a um avanço na forma de governar, em que o New Public Governance seria o último modo dominante de Administração Pública, depois do Public Administration e do New Public Management (NPM) (OSBORNE, 2006). A proposta de modos de governança adotada neste artigo segue o entendimento de Capano (2011), de que a governança engloba "todas as possibilidades que os atores interessados numa política pública encontram para resolver problemas coletivos e, portanto, qualquer forma em que o processo de formulação de políticas seja controlado" (CAPANO, 2011, p. 1625). Nessa perspectiva, a governança não é um dos modos de atuação dos governos, mas um arcabouço maior, no qual o papel dos governos varia, de acordo com o sistema adotado.

Capano (2011) propõe quatro modos de governança na política de ES: o hierárquico, o procedimental, a condução a distância e a autogovernança. No modo hierárquico, 
os governos estabelecem os objetivos do sistema e os métodos para alcançá-los. No procedimental, as Instituições de Educação Superior (IES) perseguem seus próprios objetivos, mas os governos impõem as regras. Na condução a distância, os governos assumem uma função mais regulatória, influenciando as IES não por meio de comandos diretos, mas de um conjunto de regras, incentivos financeiros e sistemas avaliativos. No modo de autogovernança, os governos deixam a arena política quase livre e intervêm somente quando necessário. Diferentes instrumentos são utilizados em cada um dos modos de governança, conforme ilustrado na Figura 1.

Figura 1 - Modos de governança em políticas de Educação Superior

Nível de especificação governamental dos meios a serem utilizados

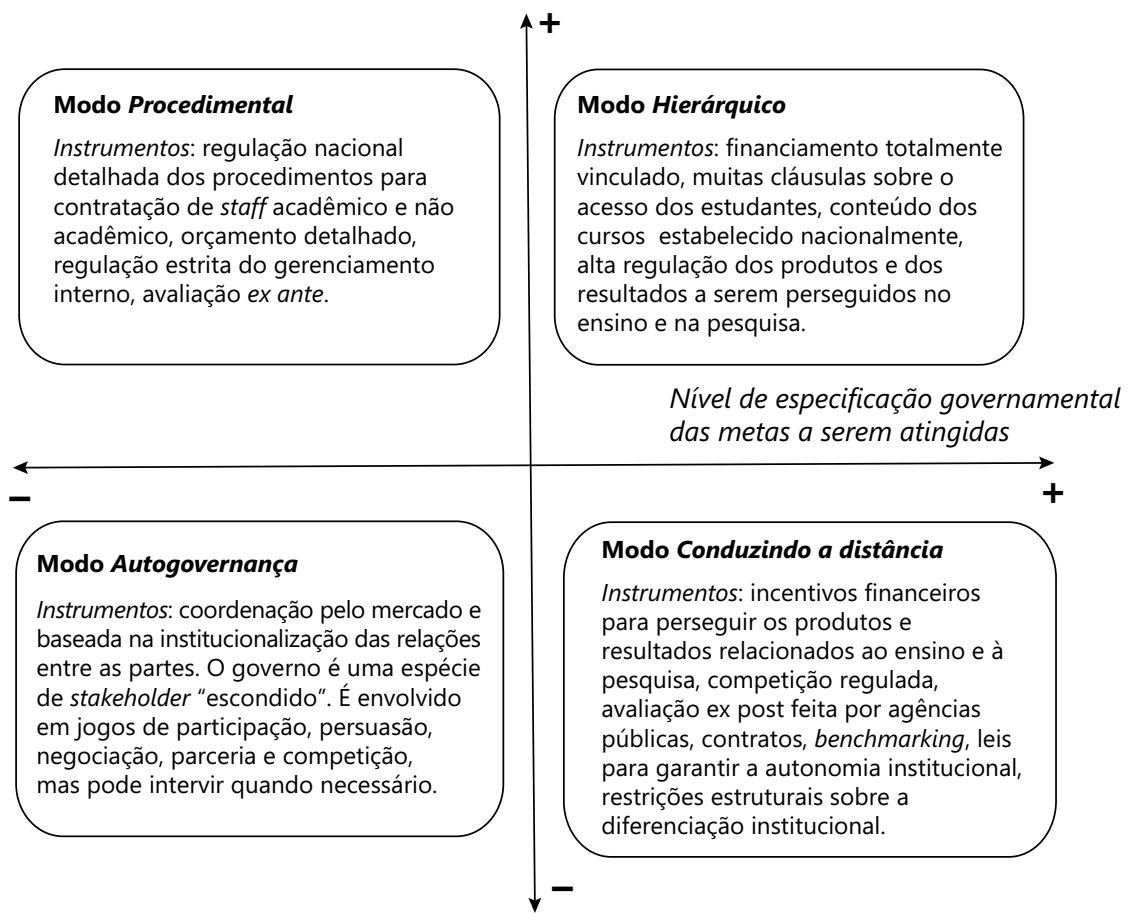

Fonte: Adaptado de Capano (2011, p. 1626, tradução livre)

Capano testa seu modelo analisando quatro países europeus: Inglaterra, Alemanha, Itália e Holanda. Seus resultados indicam que, apesar das diferenças decorrentes 
do legado histórico-institucional de cada país, tem havido certa convergência para o modo de condução a distância, em que os governos dão mais autonomia às IES, de modo a alcançar objetivos coletivos, como a expansão e a diversificação do sistema educacional. Em todos os casos, Capano argumenta que os modos de governança mudaram como consequência da ação direta dos governos, quando decidiram alterar o seu próprio papel no processo de condução das políticas. Aponta ainda que, paradoxalmente, embora se observe um afastamento dos instrumentos de controle típicos do modo procedimental, as mudanças encontradas traduzemse numa posição governamental mais restritiva em relação aos objetivos a serem alcançados (CAPANO, 2011).

Enquanto Capano percebe um protagonismo dos governos na decisão do seu papel na orientação das políticas educacionais, Afonso (2013) aponta para uma perda crescente da autonomia dos estados-nação, em função da atuação de instâncias internacionais. $\mathrm{O}$ autor argumenta que a noção de Estado Avaliador passa por diferentes fases ao longo do tempo, tendo sido marcada nos anos $1980 \mathrm{e} \mathrm{em}$ parte dos anos 1990, por uma atuação predominantemente autônoma dos Estados na condução de suas políticas educacionais. Nessa primeira fase, estabeleceram-se os sistemas de avaliação nacionais de larga escala, inclusive em países que não tinham essa tradição. A segunda fase do Estado Avaliador, que se seguiu desde o final dos anos 1990, é marcada por uma retração da atuação autônoma dos Estados, devido ao avanço das instâncias internacionais e transnacionais, como a União Europeia, a Organização para a Cooperação e Desenvolvimento Econômico (OCDE) e o Banco Mundial, além da consolidação de agências privadas e do protagonismo de agências internacionais, como a European Association for Quality Assurance in Higher Education (ENQA), na Europa. O autor ensaia, ainda, o surgimento de uma terceira fase, marcada pela crise da regulação da economia global e pela formação de uma sociedade civil mundial, com um aumento da mercadorização e da mercantilização da ES por meio de sistemas de franchising. Nessa fase, ocorrerá uma ampliação da privatização do sistema e das agências de avaliação, com a intensificação de políticas de avaliação comuns no âmbito de blocos econômicos, como União Europeia ou Mercosul (AFONSO, 2013).

O movimento detectado por Capano, de mudança no modo predominante de governança para uma condução das políticas a distância (CAPANO, 2011), é confirmado por Afonso, quando percebe a consolidação de agências avaliadoras nacionais e de uma regulação pelo conhecimento, por meio de indicadores e de políticas baseadas em desempenho. Os autores divergem, no entanto, na questão sobre como esses processos ocorrem. Enquanto Capano defende que os governos têm redefinido o seu papel ao construir novos modelos de governança, Afonso (2013) enxerga esse movimento como resultado de um projeto maior, impulsionado 
pela necessidade de acumulação capitalista, por meio da mercadorização/ mercantilização da Educação. Nessa concepção, os Estados não estariam se reposicionando, mas, paulatinamente, perdendo o seu papel na definição das políticas educacionais.

Vale destacar que, diferentemente do sistema europeu, composto principalmente de universidades públicas, na América Latina, a expansão do sistema educacional foi baseada num grande processo de mercantilização, o que tornou a América Latina e o Caribe a região com o maior setor privado de ES do mundo. Os resultados de um estudo comparativo global, realizado com dados de 2010, mostraram que a América Latina e o Caribe concentravam 48,8\% das matrículas de ES no setor privado, seguida pela Ásia (42,1\%) e pelos Estados Unidos (27,5\%). Em regiões como Europa e Canadá, Austrália e Nova Zelândia (CANZ), as matrículas no setor privado foram de apenas $14,9 \%$ e $10,1 \%$, respectivamente (LEVY, 2018). A expansão pela via privada foi o caminho trilhado pelos governos latino-americanos para incluir os grupos tradicionalmente fora do sistema. Para isso, os governos tiveram que lidar com os desafios de garantir a qualidade e a responsabilização das instituições pelos serviços prestados, o que gerou mudanças nos modos de governança adotados.

Baseado nesse arcabouço teórico, este artigo advoga a necessidade de uma análise dessas mudanças, focando em dois aspectos, que, embora pareçam antagônicos, podem ser explorados em sua complementaridade. Na linha proposta por Capano (2011), deve-se focar no como, e, para isso, observar os instrumentos adotados pelos governos e o seu reposicionamento na orientação das políticas educacionais, a partir da virada neoliberal ocorrida nos anos 1990. Complementarmente, na linha seguida por Afonso, deve-se observar como essas políticas são influenciadas pelo movimento global de mercantilização da Educação, procurando compreender como as nações lidam com a intensificação dos sistemas de avaliação transnacionais.

\section{Aspectos metodológicos}

Este é um estudo de caso único, com foco nas políticas de ES brasileiras, implementadas no período de 1995 a 2017. Como o objetivo era utilizar os modelos teóricos em contextos de participação intensa do setor privado na ES, optou-se pelo Brasil, não só pela conveniência de acesso aos dados, mas pelo tamanho do sistema brasileiro nos contextos regional e global. Na América Latina, o Brasil é o único país entre os cinco primeiros do mundo, em número total de matrículas, totalizando 8.319.089 matrículas em 2016, atrás apenas de gigantes como: China (43.886.104), a Índia (32.391.800) e os Estados Unidos (19.288.424) (OECD, 2020). A comparação da OCDE não inclui a Rússia, o que 
poderia colocar o Brasil na quinta posição mundial. Em termos de percentual de matrículas no setor privado, dados de 2010 mostravam o Brasil na terceira posição no ranking mundial, com $72,7 \%$, atrás apenas da República da Coreia (80,7\%) e do Japão (78,6\%) (LEVY, 2018).

O ponto de partida para a análise foi o momento em que o país iniciou um grande movimento de reforma da administração pública, em 1995, com base nas orientações do NPM e no contexto das reformas neoliberais (BRESSER PEREIRA, 1996). Nesse período, o Brasil consolidou, pela primeira vez, um sistema nacional de avaliação da ES. A análise estende-se até 2017, último governo com uma gestão completa. Embora passe por mandatos de quatro presidentes, Fernando Henrique Cardoso (1995-2002), Luís Inácio Lula da Silva (2003-2010), Dilma Rousseff (2011-2016) e Michel Temer (2016-2017), a análise não tem como objetivo estabelecer comparações entre os diferentes governos.

O método utilizado foi a pesquisa documental, considerando trabalhos acadêmicos, a legislação nacional e as bases de dados oficiais. As categorias de análise foram estabelecidas a partir do referencial teórico, com foco nos instrumentos de políticas característicos dos modos de governança propostos por Capano (2011) e nas fases do Estado Avaliador, estabelecidas por Afonso (2013). Foi utilizada a análise de conteúdo para classificar a informação nas categorias propostas e detalhadas no Quadro 1.

Quadro 1 - Categorias de análise

\begin{tabular}{|l|l|}
\hline \multirow{3}{*}{$\begin{array}{l}\text { Quarantia de } \\
\text { Quadade }\end{array}$} & $\begin{array}{l}\text { Responsabilidade pela avaliação } \\
\text { Agência pública ou privada } \\
\text { Presença de agências privadas e/ou internacionais }\end{array}$ \\
\cline { 2 - 3 } & $\begin{array}{l}\text { Avaliação ex ante ou ex post } \\
\text { Foco nos insumos, processos e/ou nos resultados } \\
\text { Instrumentos utilizados }\end{array}$ \\
\hline Regulação \\
(autonomia) & $\begin{array}{l}\text { Regras para abertura e criação de novos cursos } \\
\text { Sistema de recompensas e puniçães } \\
\text { Regras para contratação de staff acadêmico e não acadêmico } \\
\text { Determinação do conteúdo dos cursos (curriculum) } \\
\text { Regras de organização e gestão interna das instituições }\end{array}$ \\
\hline $\begin{array}{l}\text { Mecanismos de } \\
\text { financiamento }\end{array}$ & $\begin{array}{l}\text { Nível de vinculação e detalhamento do financiamento } \\
\text { Sistema de incentivos financeiros } \\
\text { Empréstimos estudantis e bolsas de estudo }\end{array}$ \\
\hline Metas Sistêmicas & $\begin{array}{l}\text { Estabelecimento de metas para o sistema } \\
\text { Monitoramento das metas }\end{array}$ \\
\hline Acesso dos & $\begin{array}{l}\text { Processos de seleção de estudantes } \\
\text { Políticas de estímulo }\end{array}$ \\
\hline
\end{tabular}

Fonte: Elaboração dos autores (2020). 
Foram considerados na análise apenas os cursos de Graduação presenciais, por isso a categoria pesquisa não foi incluída, pois no Brasil, ela é tratada no âmbito da Pós-Graduação e possui legislação e modelo de avaliação específicos. Os cursos a distância não foram considerados, pois o fenômeno da Educação a distância possui particularidades que extrapolam o escopo desta pesquisa.

\section{Resultados e discussão}

Nesta seção, são apresentados os resultados e as discussões feitas, conforme as categorias de análise utilizadas.

\subsection{Garantia da Qualidade}

O primeiro modelo de avaliação nacional da ES brasileira foi adotado em 1995, no governo Fernando Henrique Cardoso, e era composto de um exame nacional para avaliar o desempenho dos graduandos e de mecanismos para avaliar as condições de oferta dos cursos e das instituições. Inspeções in loco feitas por especialistas eram o principal instrumento para avaliar a qualidade dos cursos. A avaliação foi destinada às IES do sistema federal, que inclui instituições públicas federais e privadas. As IES do nível estadual podiam ser avaliadas por seus respectivos estados. Apesar das Secretarias do Ministério da Educação (MEC) serem incialmente responsáveis pela implementação dos processos de avaliação, em 2001, essa responsabilidade foi transferida para o Instituto Nacional de Estudos e Pesquisas Anísio Teixeira (Inep).

Em 2004, no governo Luís Inácio Lula da Silva, visando a superar problemas do sistema anterior, foi instituído o Sistema Nacional de Avaliação da Educação Superior (Sinaes), cuja implementação ficou a cargo também do Inep, sob a coordenação e a supervisão da Comissão Nacional de Avaliação da Educação Superior (Conaes) ${ }^{1}$. Dentre as críticas, apontava-se que a avaliação estava servindo à produção de rankings e estimulando uma competitividade desnecessária entre as IES, além de estar mais voltada à regulação do que à melhoria da qualidade do sistema (BRASIL 2004a).

O Sinaes procurou equilibrar as avaliações externa e interna, empoderando a autoavaliação como instrumento para avaliar a qualidade das instituições. No entanto, um Exame Nacional de Avaliação do Desempenho dos Estudantes (Enade) e as

\footnotetext{
A Conaes é um órgão colegiado, criado pela Lei do Sinaes, que tem em sua composição representantes do Inep, da Fundação Coordenação de Aperfeiçoamento de Pessoal de Nível Superior (Capes), do MEC, do corpo docente, discente e técnico-administrativo das IES, além de membros, indicados pelo Ministro da Educação, escolhidos entre cidadãos com notório saber científico, filosófico e artístico, e reconhecida competência em avaliação ou gestão da ES. Devido à sua composição heterogênea, que inclui agentes governamentais e não-governamentais, a Conaes atua como um espaço privilegiado de debate e validação sobre quaisquer modificações sugeridas ao Sinaes.
} 
inspeções in loco ainda foram os principais mecanismos para avaliar a qualidade dos cursos (BRASIL 2004b). Em 2008, uma grande mudança foi feita no sistema, com a criação de dois indicadores, o Conceito Preliminar de Curso (CPC) e o Índice Geral de Avaliação dos Cursos da Instituição (IGC), que permitiram avaliar cursos e instituições, sem a necessidade de visitas in $l o c o^{2}$ e dispensar os cursos considerados satisfatórios de novas visitas em processos regulatórios. Pelo governo, os indicadores foram justificados pela expansão do sistema e pela falta de mão de obra para realizar todas as inspeções necessárias (FERNANDES et al., 2009).

Pela comunidade acadêmica, no entanto, a mudança foi recebida com críticas, como a desvalorização da autoavaliação em relação à regulação e um retorno ao sistema que se desejava superar (LACERDA; FERRI; DUARTE, 2016; VERHINE; DANTAS; SOARES, 2006). Apesar dos indicadores não serem publicados em formatos de rankings, seu uso está naturalmente inserido numa lógica de comparação entre as instituições.

De maneira resumida, o Brasil conta, atualmente, com cinco indicadores de desempenho das instituições e dos cursos, apresentados numa escala de 1 a 5 , em que os conceitos 3, 4 e 5 são considerados satisfatórios e os conceitos 1 e 2, insatisfatórios. Como os indicadores são padronizados estatisticamente, a maioria dos cursos atinge resultados satisfatórios. A Figura 2 mostra o percentual de cursos por faixa do CPC, no triênio 2015-2017, quando um total de 21.479 cursos foram avaliados.

Figura 2 - Resultados do Conceito Preliminar de Curso (2015-2017)

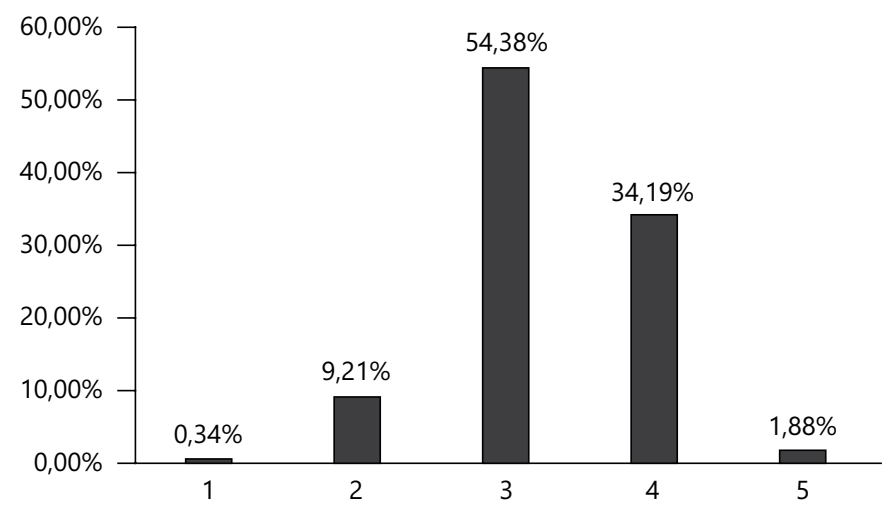

Fonte: Elaboração dos autores (INEP, 2016; 2017, 2018a)

2 O cálculo desses indicadores foi possível por causa dos dados disponíveis no Inep, decorrentes do Censo da Educação Superior, e na Capes, decorrentes dos resultados da avaliação da Pós-Graduação stricto sensu. As IES têm um papel fundamental na prestação de informações confiáveis para a construção dessas bases. 
Como visto, mais de $90 \%$ dos cursos foram considerados satisfatórios. Assim, no que se refere à responsabilização, apesar dos resultados da avaliação serem ligados às políticas regulatórias, eles, raramente, funcionam como um mecanismo real de punição, já que os resultados padronizados fazem a maioria dos cursos alcançar níveis satisfatórios. Além disso, os cursos com resultados insatisfatórios podem recorrer em diferentes instâncias, o que torna uma punição, como fechar uma instituição, muito rara. Observa-se que os governos tentaram encontrar um equilíbrio entre avaliação e regulação, com alguma variação ao longo do tempo. Como exemplo, uma punição para as IES privadas era ter o direito de fazer parte do Fundo de Financiamento ao Estudante do Ensino Superior (Fies) condicionado aos resultados do Enade, mas isso foi relaxado em 2010, quando começou-se considerar qualquer indicador de qualidade, incluindo os resultados das inspeções in loco. Dias Sobrinho (2010) argumenta que avaliações constituídas como políticas de controle atendem aos interesses do mercado, pois são pouco eficientes para evitar a expansão de instituições e de cursos de baixa qualidade. Com o tamanho do setor privado no Brasil, e a presença de grandes grupos empresariais de capital aberto, é preciso considerar que a ação estatal está também sujeita às pressões de grupos de interesse ao longo do tempo.

A avaliação no Brasil é, como visto, uma reponsabilidade do Estado. Agências privadas de avaliação não atuam no país e, embora a autoavaliação seja parte do processo avaliativo, ela não dispensa a avaliação feita pelo Estado. Em relação aos organismos internacionais, o Brasil é signatário do acordo sobre a criação e a implementação de um sistema de credenciamento de cursos de Graduação para o reconhecimento regional da qualidade acadêmica dos respectivos diplomas no Mercosul e nos Estados Associados (Sistema Arcu-Sul), desde 2008 (MERCOSUL, 2008). O sistema é gerenciado pela Rede de Agências Nacionais de Acreditação (Rana) e, atualmente, composta pela Argentina, pela Bolívia, pelo Brasil, pelo Chile, pela Colômbia, pelo Paraguai, pelo Uruguai e pela Venezuela. O sistema de acreditação é feito por meio de convocações periódicas e a participação das instituições é voluntária. O impacto da acreditação no âmbito do Arcu-Sul ainda é pequeno, tendo em vista que apenas 32 cursos foram acreditados em 2012 (BRASIL, 2013a). O Brasil participa também, desde 2004, da Rede Ibero-americana para Acreditação da Qualidade da Educação Superior (Riaces), uma associação sem fins lucrativos que reúne agências de avaliação e de credenciamento de 18 países ibero-americanos (RIACES, 2020). Santos e Leite apontam que a Riaces tem se articulado com atores globais, como a Comissão Europeia, a Organização das Nações Unidas para a Educação, a Ciência e a Cultura (Unesco) e o Banco Mundial e empreendido esforços para dialogar com redes de outros continentes. Os autores questionam em que medida sua atuação caminha para a afirmação do caráter hegemônico 
de um modelo de qualidade global, amparada por recursos financeiros atrelados a agências do capitalismo mundial (SANTOS; LEITE, 2019). Não foram encontrados, no entanto, registros da atuação do Brasil na rede ou dos resultados dessa participação.

Vale destacar que, em 2017, a Conaes, com respaldo do MEC, intermediou e viabilizou a contratação da OCDE para avaliar a relevância, a efetividade e a eficiência dos processos de avaliação adotados no país, chancelando, dessa forma, a capacidade técnica do organismo internacional para a meta-avaliação do Sinaes. O relatório final, publicado em 2018, recomenda a autoacreditação de cursos para instituições com reconhecida capacidade de autoavaliação e para as demais, que as autoridades brasileiras considerem a transferência de certas tarefas para avaliadores profissionais, deixando a avaliação por pares livre para focar em aspectos relacionados ao processo de aprendizagem. Aponta, ainda, um possível conflito de interesse na atuação do MEC, responsável pela condução e pela regulação das instituições públicas federais, sugerindo a criação de uma agência autônoma, composta por avaliadores profissionais e acadêmicos (OECD, 2018). A resposta do Inep veio no ano seguinte, evidenciando o mal-estar do Instituto por ter sido responsável pelo pagamento do produto mas só ter tido acesso a ele depois da própria imprensa, que já veiculava os resultados negativos da meta-avaliação feita pela organização internacional. O Inep consolida críticas ao relatório, relacionadas ao seu rigor teórico-metodológico, especialmente a fragilidade das evidências coletadas para embasar tanto as críticas quanto as recomendações feitas (INEP, 2019).

Ainda em termos internacionais, observa-se, a partir dos anos 2000, a proliferação de rankings para avaliar a qualidade das universidades em nível global. Seus resultados vão se legitimando social e academicamente à medida em que o posicionamento nos rankings é interpretado como comprovação de qualidade. Uma questão que se coloca é em que medida os rankings incorporam critérios que se refletem nos processos de autoavaliação ou passam a nortear a própria gestão interna da qualidade das IES (ANDRIOLA; ARAÚJO, 2018).

\subsection{Regulação}

O Estado brasileiro é responsável pela autorização, pelo reconhecimento e pela renovação de reconhecimento dos cursos e pelo credenciamento e pelo recredenciamento das instituições, de acordo com os resultados da avaliação (BRASIL, 1996). Os processos passam pelo Ministério da Educação e pelo Conselho Nacional de Educação (CNE), como instância deliberativa e recursal. A importância crescente das atividades de regulação e de supervisão do sistema 
resultaram na criação da Secretaria de Regulação e Supervisão da Educação Superior (Seres) no MEC, em 2011. Vale destacar a tentativa de criação do Instituto Nacional de Supervisão e Avaliação da Educação Superior (Insaes), projeto de lei em tramitação no Congresso desde 2012 (BRASIL, 2012c).

A regulação tem como desafio lidar com um sistema em crescimento e estabelecer regras para diferentes tipos de IES, respeitando seus distintos graus de autonomia. A Tabela 1 apresenta o crescimento do número de IES por organização acadêmica de 1997 a 2017.

Tabela 1 - Crescimento das instituições por organização acadêmica (1997-2017)

\begin{tabular}{cccccc}
\hline \multirow{2}{*}{$1997^{\text {a }}$} & Universidades & Centros Universitários & Outros & Total \\
\cline { 3 - 6 } & Pública & 77 & 1 & 133 & 211 \\
& Privada & 73 & 90 & 526 & 689 \\
& Total & $\mathbf{1 5 0}$ & $\mathbf{9 1}$ & $\mathbf{6 5 9}$ & $\mathbf{9 0 0}$ \\
\hline \multirow{2}{*}{2007} & Pública & 96 & 4 & 149 & 249 \\
& Privada & 87 & 116 & 1829 & 2032 \\
& Total & $\mathbf{1 8 3}$ & $\mathbf{1 2 0}$ & $\mathbf{1 9 7 8}$ & $\mathbf{2 2 8 1}$ \\
\hline \multirow{2}{*}{2017} & Pública & 106 & 8 & 182 & 296 \\
& Privada & 93 & 181 & 1.878 & 2.152 \\
& Total & $\mathbf{2 3 9}$ & $\mathbf{1 8 9}$ & $\mathbf{2 . 0 2 0}$ & $\mathbf{2 . 4 4 8}$ \\
\hline
\end{tabular}

Fonte: (INEP, 1998; 2008; 2018a)

aEm 1997, os Centros Universitários incluem as faculdades integradas.

O Brasil adotou diferentes formas de classificação das IES ao longo dos anos (BRASIL, 1997; 2004c), reduzida, em 2006, a universidades, centros universitários e faculdades (BRASIL, 2006; 2017). Em geral, as universidades e os centros universitários mantiveram sua autonomia para criar e extinguir cursos. As demais precisam submeter suas demandas por novos cursos a processo de autorização controlado pelo MEC. Recentemente, tem havido alguma flexibilização nesse processo, como a dispensa das visitas in loco se as faculdades atenderem a determinadas condições (BRASIL, 2017).

O MEC é também responsável pela supervisão das IES. A Seres pode determinar medidas preventivas, como suspender a admissão de novos estudantes, a oferta de cursos, prerrogativas de autonomia ou o acesso a programas de financiamento. Penalidades podem ser aplicadas se as irregularidades não forem remediadas, 
como a desativação de cursos e instituições, mas o processo envolve possibilidades recursais, tanto no MEC, quanto no CNE (BRASIL, 1996; 2017).

A autonomia para contratar o corpo docente depende da categoria administrativa e da organização acadêmica das IES. Universidades públicas federais precisam cumprir a legislação específica de servidores públicos federais (BRASIL, 1991), mas têm autonomia para selecionar seu corpo docente e seu quadro administrativo. Em universidades privadas, pelo menos um terço do corpo docente precisa ter título de Mestre ou Doutor e ser contratado em tempo integral, enquanto nos centros universitários, essa proporção é de um quinto. Faculdades têm autonomia nesses quesitos, mas o sistema de avaliação pressiona os cursos a aumentarem o número de Mestres e Doutores em tempo integral, para obter indicadores satisfatórios. Em relação aos currículos dos cursos, desde 1996, o currículo mínimo obrigatório foi extinto e o CNE ficou responsável por publicar diretrizes curriculares nacionais (DCN) (BRASIL, 1995).

A organização e a gestão interna dos cursos também estão relacionadas ao seu perfil administrativo e acadêmico. A estrutura das universidades públicas foi basicamente definida pela Reforma Universitária de 1968, que criou os departamentos. Apesar de diferentes estruturas serem permitidas, a maior parte das universidades manteve um alto nível de departamentalização. A existência de instâncias colegiadas de deliberação é obrigatória (BRASIL, 1996). Apesar da autonomia prevista na Constituição Federal de 1988 (BRASIL, 2016), as IES públicas são amarradas a uma extensa legislação em termos de contratação de pessoas, planos de cargos e de salários e compras públicas. As instituições privadas gozam naturalmente de maior autonomia, mas também são afetadas pelas regras governamentais. A avaliação considera dimensões, como a organização e a gestão institucional, além da sustentabilidade financeira das IES. Os processos regulatórios exigem um Plano de Desenvolvimento Institucional, regimento interno e informações sobre o quadro diretor (BRASIL, 2017). As IES também são obrigadas a manter Comissões Internas de Avaliação (CPA) (BRASIL, 2004b).

Como visto, a função regulatória do governo pode variar de acordo com os contextos específicos. As regras impostas pelos governos para criar e para extinguir cursos têm sido suavizadas ao longo do tempo, o que pode ser atribuído a fatores diversos, como o crescimento do sistema ou a ação dos atores interessados na política. A capacidade reguladora dos governos mostra-se, assim, dependente de sua capacidade político-administrativa para lidar com a dimensão e com a complexidade do sistema e com a atuação dos grupos que atuam no processo político. 


\subsection{Mecanismos de Financiamento}

A forma de financiamento das Instituições Federais de Educação Superior (Ifes) mantidas pela União é mista, combinando um orçamento incremental com uma parte baseada em critérios de desempenho. As Ifes são públicas e gratuitas e seus recursos orçamentários são assegurados constitucionalmente e por lei complementar. Em 2013, o MEC promoveu modificações nos critérios para distribuição dos recursos de custeio e de capital, instituindo a Matriz de Orçamento de Outros Custeios e Capital (Matriz OCC), e considerando indicadores relativos ao número de alunos matriculados e concluintes, relação aluno professor e à qualidade dos cursos, todos produzidos pelo MEC (BRASIL, 2013b).

As instituições privadas de ES têm orçamento próprio, decorrente da cobrança de mensalidades pelos serviços prestados, mas também são contempladas com benefícios fiscais decorrentes da oferta de bolsas estudantis do Programa Universidade para Todos (Prouni) (BRASIL, 2005). O Estado tem estimulado ainda a expansão do setor privado por meio do Fies, programa criado em 1999, para financiar estudantes de baixa renda de cursos de graduação privados não gratuitos, com resultados satisfatórios no sistema de avaliação (BRASIL, 2001a).

O Fies e o Prouni têm sido importantes mecanismos de expansão da ES nas instituições privadas. O número de contratos do Fies passou de $77.212 \mathrm{em} 2005$ para 732.243 em 2014. No mesmo período, o número de bolsas do Prouni subiu de 95.580 para 223.579 (CORBUCCI; KUBOTA; MEIRA, 2016). Em 2015 e 2017, o Fies passou por reformas visando a diminuir os custos do programa e os níveis de inadimplência. Dentre outras medidas, estabeleceu-se o realinhamento dos critérios de renda, o fim do financiamento integral, o aumento das coparticipações e da taxa de juros, a redução do número de vagas e a possibilidade de que a amortização possa ser consignada em folha de pagamento, aproximando o programa dos modelos contingentes à renda (PIRES, 2018).

\subsection{Metas sistêmicas}

Metas sistêmicas têm sido estabelecidas por meio dos Planos Nacionais de Educação (PNE), publicados para o decênio, em 2001 (BRASIL, 2001b) e depois em 2014, após atraso de quase quatro anos de tramitação no Congresso Nacional (BRASIL, 2014). Das 20 metas estabelecidas para a Educação no PNE 2014, duas são diretamente relacionadas à ES. A meta 12 estabelece a necessidade de aumentar a taxa bruta de matrículas para $50 \%$ e a taxa líquida para $33 \%$ da população entre 18 e 24 anos e expandir a proporção de novas matrículas no setor público para no mínimo $40 \%$. A meta 13 propõe aumentar a proporção 
de professores mestres e doutores para $75 \%$, com pelo menos $35 \%$ de doutores (BRASIL, 2014).

Em 2019, a taxa bruta de matrículas alcançou 37,4\% e a taxa líquida de escolarização $25,5 \%$. Desigualdades regionais no acesso da população entre 18 e 24 anos foram observadas nos dois indicadores, com as regiões Norte e Nordeste apresentando taxas menores que a média nacional (INEP, 2020). Em relação à titulação do corpo docente, em 2015 a meta já havia sido alcançada $(75,4 \%)$ e o mínimo de 35\% de professores doutores já era realidade em 2014 (35,5\%), quando o PNE foi publicado. Desigualdades regionais também foram observadas, sendo que em 2018 a região Norte ainda não tinha alcançado a meta (INEP, 2020).

Considerando os objetivos do PNE 2014, o Brasil mostra-se inconsistente em termos de metas para a ES. Conforme demonstrado, as metas estabelecidas sofrem a influência das disparidades e desigualdades regionais. Até agora, os atuais instrumentos políticos, especialmente o sistema de avaliação único para todo o sistema, não parecem contribuir para pensar os objetivos globais como alvos coletivos. Os desafios permanecem para elevar as taxas de matrícula bruta e líquida em algumas regiões do país, bem como para aumentar a proporção de professores mestres e doutores, o que se torna mais complexo no contexto de crise econômica, restrições orçamentárias e altas taxas de desemprego por que passa o país. Outros desafios incluem a retenção dos estudantes do sistema, reduzindo as taxas de evasão (LIMA JUNIOR et al., 2019) e a inserção efetiva dos egressos do mercado de trabalho (ALMEIDA et al., 2020).

\subsection{Acesso dos estudantes}

Os mecanismos de acesso à ES no Brasil têm sido tradicionalmente os vestibulares aplicados pelas próprias instituições. Em 1998, no entanto, o MEC criou o Exame Nacional do Ensino Médio (Enem), que funciona como subsídio para o acesso à ES (BRASIL, 1998). Em 2017, 6.731.341 estudantes se inscreveram no Enem (INEP, 2018b).

Desde 2004, o Brasil intensificou a discussão sobre políticas de ação afirmativa para garantir o acesso de estudantes de baixa renda, pretos e indígenas à ES e, em 2012, a questão transformou-se em lei. O MEC determinou que instituições federais ligadas ao Ministério deveriam reservar, em cada processo seletivo, pelo menos $50 \%$ de suas vagas a estudantes que tivessem completado o Ensino Médio em escolas públicas. Essas vagas deveriam ser preenchidas por um percentual mínimo correspondente ao total de pretos, pardos e indígenas do estado da IES, desde que participantes do Enem (BRASIL, 2012a; 2012b). 
Ainda em 2012, o MEC criou o Sistema de Seleção Unificada (Sisu), que permitiu aos estudantes se candidatar a diferentes vagas pelo país, utilizando os resultados do Enem. Do total de 2.152.752 admissões na ES em 2017, 623.299 (29\%) foram por meio do Enem. Considerando-se apenas o setor público, esse percentual cresce para $52 \%$, contra $22 \%$ nas IES privadas (INEP, 2018b). A consolidação de processos seletivos nacionais e regionais como forma de superar exames isolados foi estabelecida como uma estratégia do PNE 2014 para alcançar a meta 12 (BRASIL, 2014).

\section{Conclusões}

A análise das mudanças ocorridas no modo de governança das políticas de ES, a partir dos anos 1990, evidencia que o Estado brasileiro continua desempenhando um papel importante na condução do sistema de ES do Brasil. O governo está presente em todas as categorias analisadas: é responsável pelo sistema de avaliação por meio de uma agência pública nacional, estabelece as principais regras para o funcionamento e manutenção do sistema e fornece mecanismos de financiamento para garantir sua expansão. Nesse sentido, adequa-se ao modo de condução a distância. Além disso, estabelece diretrizes curriculares nacionais e mantém e reforça um exame nacional como um dos instrumentos de acesso ao ES, utilizando assim instrumentos típicos do modelo hierárquico. Pode-se dizer que o modo de governança das políticas de ES no Brasil é predominantemente de condução a distância, com traços do modo hierárquico.

Além disso, os governos têm ainda preservado sua autonomia em relação aos organismos internacionais na avaliação da qualidade do sistema, o que indica um posicionamento na primeira fase do Estado Avaliador. A participação em redes internacionais se dá no âmbito regional da América Latina, o que pode se traduzir tanto num movimento contra hegemônico em relação ao capitalismo global, quanto num primeiro passo em sua direção (SANTOS; LEITE, 2019). A contratação da OCDE durante o governo Temer dá indícios de uma aproximação com a organização internacional. Esses movimentos, se feitos sem o devido planejamento e debate interno, podem resultar num mero "empréstimo de políticas", descontextualizado e sem vantagens claras para o país, justificados simplesmente pelo discurso da suposta modernização alcançada pelos países desenvolvidos (AFONSO, 2013). Observa-se que, no caso das universidades, a colocação nos rankings internacionais tem assumido uma importância crescente como sinônimo da qualidade, mas ainda sem uma ação estatal consolidada neste sentido.

Apesar das muitas políticas implementadas pelos diferentes governos do Brasil, desde a reforma do Estado nos anos 1990, seu principal papel tem sido o de 
garantir que o sistema continue a expandir, fornecendo regras e mecanismos de financiamento, especialmente para a expansão sustentável do setor privado. Esse desafio pode ser maior ou menor conforme o momento econômico vivido pelo país. Com o acirramento da crise fiscal e econômica, o debate sobre a diversificação da matriz de financiamento das Ifes tende a se intensificar.

Recomenda-se que estudos sobre políticas de ES considerem o interrelacionamento entre avaliação, regulação e financiamento, de modo a capturar os diversos instrumentos utilizados pelos governos e a dinâmica de formação e de mudança nos modos de governança. Se os governos continuam atuando como atores-chave na orientação das políticas educacionais, cabem investigações sobre como atuam os grupos interessados na política (JENKINS-SMITH et al., 2014; 2018) e como influenciam os processos de mudança institucional (MAHONEY; THELEN, 2010). Estudos que investiguem o processo de aprendizado sobre a política (policy learning) e sua influência nos processos de tomada de decisão dos policymakers também são importantes (HEIKKILA; GERLAK, 2013; JENKINS-SMITH et al., 2014; 2018), bem como estudos que analisem o desenho das políticas (policy design), especialmente o modo como os governos atuam para promover mudanças que desafiam o status quo (CAPANO, 2018). Por fim, estudos comparativos podem ajudar a observar similaridades e diferenças entre os instrumentos de políticas educacionais utilizados, e, especialmente, como os governos atuam para fazer frente à complexidade dos desafios que se impõem aos sistemas de ES. 


\title{
Rowing or steering? Modes of governance for Higher Education policies in Brazil post 1990
}

\begin{abstract}
This article aims to analyze the role that governments in Brazil have played in the conduct of Higher Education policies, taking as reference a typology that establishes four modes of governance for Higher Education: hierarchical, procedural, steering at distance and self-governance. In addition, it considers three different phases of the of the "evaluator" State to analyze its degree of autonomy vis-à-vis international bodies. Based on the theoretical framework adopted, a case study of the Brazilian Higher Education system is conducted, from 1995 to 2017, through documentary research and content analysis. The results indicate that the mode of governance of higher education policies predominant in Brazil is the steering at distance mode, with traits of the hierarchical mode. In addition, it is evident that the State maintains relative autonomy vis-à-vis international organizations, showing signs of approximation with the Organisation for Economic Co-operation and Development.
\end{abstract}

Keywords: Higher Education. Governance. Quality Assurance.

\section{¿Remando o guiando el barco? Modelos de gobernanza para las políticas de Educación Superior en Brasil después de 1990}

\section{Resumen}

Este artículo tiene como objetivo analizar el papel que han desempeñado los gobiernos de Brasil en la conducción de las políticas de Educación Superior, tomando como referencia una tipología que establece cuatro modos de gobernanza para este tipo de Educación: la jerárquica, la procedimental, la de conducción a distancia y el autogobierno. Además, considera tres fases distintas del Estado evaluador para analizar su grado de autonomía frente a los organismos internacionales. Con base en el marco teórico adoptado, se realiza un estudio de caso del sistema de Educación Superior brasileño, de 1995 a 2017, a través de la investigación documental y el análisis de contenido. Los resultados indican que el modo de gobernanza de las políticas de Educación Superior en Brasil es, predominantemente, la conducción a distancia, con vestigios del modo jerárquico. Además, es evidente que el Estado mantiene una relativa autonomía frente a los organismos internacionales, mostrando signos de aproximación con la Organización para la Cooperación y el Desarrollo Económicos.

Palabras clave: Educación Superior. Gobernanza. Evaluación de Calidad. 


\section{Referências}

AFONSO A. J. Mudanças no Estado-avaliador: comparativismo internacional e teoria da modernização revisitada. Revista Brasileira de Educação, Rio de Janeiro, v. 18, n. 53, p. 267-284, abr.jun. 2013. https://doi.org/10.1590/S1413-24782013000200002

ALMEIDA, A. N. et al. Effectiveness of public university expansion in Brazil: comparison between the situation of graduated and dropout students. Ensaio: Avaliação e Politicas Públicas em Educação, Rio de Janeiro, v. 28, n. 107, p. 457-479, Apr./Jun. 2020. https://doi.org/10.1590/s0104-40362019002701864

ANDRIOLA, W. B.; ARAÚJO, A. C. Uso de indicadores para diagnóstico situacional de Instituições de Ensino Superior. Ensaio: Avaliação e Políticas Públicas em Educação, Rio de Janeiro, v. 26, n. 100, p. 645-663, jul./set. .2018. https://doi.org/10.1590/s0104-40362018002601062

BRASIL. Decreto n 2.207 , de 15 de abril de 1997. Regulamenta, para o Sistema Federal de Ensino, as disposições contidas nos arts. 19, 20, 45, 46 e $\S 1$ 1o, 52, parágrafo único, 54 e 88 da Lei no 9.394, de 20 de dezembro de 1996, e dá outras providências. Diário Oficial da União, Brasília, DF, 16 abr. 1997.

BRASIL. Decreto $\mathrm{n}^{0} 5.225$, de 1 de outubro de 2004c. Altera dispositivos do Decreto no 3.860, de 9 de julho de 2001, que dispõe sobre a organização do ensino superior e a avaliação de cursos e instituições, e dá outras providências. Diário Oficial da União, Brasília, DF, 4 out. 2004.

BRASIL. Decreto ${ }^{\circ} 5.773$, de 9 de maio de 2006. Dispõe sobre o exercício das funções de regulação, supervisão e avaliação de instituições de Educação Superior e cursos superiores de graduação e sequenciais no sistema federal de ensino. Diário Oficial da União, Brasília, DF, 10 maio 2006.

BRASIL. Decreto $\mathrm{n}^{\mathrm{0}} 7.824$, de 11 de outubro de 2012. Regulamenta a Lei $\mathrm{n}^{\circ} 12.711$, de 29 de agosto de 2012, que dispõe sobre o ingresso nas universidades federais e nas instituições federais de ensino técnico de nível médio. Diário Oficial da União, Brasília, DF, 16 out. 2012a.

BRASIL. Decreto $n^{\circ} 9.235$, de 15 de dezembro de 2017. Dispõe sobre o exercício das funções de regulação, supervisão e avaliação das instituições de Educação Superior e dos cursos superiores de graduação e de pós-graduação no sistema federal de ensino. Brasília, DF, 18 dez. 2017. 
BRASIL. Lei no ${ }^{\circ} 8.112$, de 11 de dezembro de 1990. Dispõe sobre o regime jurídico dos servidores públicos civis da União, das autarquias e das fundações públicas federais. Diário Oficial da União, Brasília, DF, 19 abr.1991.

BRASIL. Lei $\mathrm{n}^{\circ}$ 9.131, de 24 de novembro de 1995. Altera dispositivos da Lei no 4.024, de 20 de dezembro de 1961, e dá outras providências. Diário Oficial da União, Brasília, DF, 25 nov. 1995.

BRASIL. Lei n ${ }^{\circ}$ 9.394, de 20 de dezembro de 1996. Estabelece as diretrizes e bases da educação nacional. Diário Oficial da União, Brasília, DF, 23 dez. 1996.

BRASIL. Lei $\mathrm{n}^{\circ}$ 10.172, de 9 de janeiro de 2001. Aprova o Plano Nacional de Educação e dá outras providências. Diário Oficial da União, Brasília, DF, 10 jan. $2001 b$.

BRASIL. Lei ${ }^{\circ}$ 10.260, de 12 de julho de 2001. Dispõe sobre o Fundo de Financiamento ao estudante do Ensino Superior e dá outras providências. Diário Oficial da União, Brasília, DF, 13 jul. 2001a.

BRASIL. Lei $\mathrm{n}^{\mathrm{o}}$ 10.861, de 14 de abril de 2004. Institui o Sistema Nacional de Avaliação da Educação Superior - SINAES e dá outras providências. Diário Oficial da União, Brasília, DF, 15 abr. 2004b.

BRASIL. Lei $\mathrm{n}^{\circ} 11.096$, de 13 de janeiro de 2005. Institui o Programa Universidade para Todos - PROUNI, regula a atuação de entidades beneficentes de assistência social no ensino superior; altera a Lei no 10.891, de 9 de julho de 2004, e dá outras providências. Diário Oficial da União, Brasília, DF, 14 jan. 2005.

BRASIL. Lei $\mathrm{n}^{\mathrm{o}}$ 12.711, de 29 de agosto de 2012. Dispõe sobre o ingresso nas universidades federais e nas instituições federais de ensino técnico de nível médio e dá outras providências. Diário Oficial da União, Brasília, DF, 30 ago. 2012 b.

BRASI. Lei $\mathrm{n}^{\mathrm{o}}$ 13.005, de 25 de junho de 2014. Aprova o Plano Nacional de Educação - PNE e dá outras providências. Diário Oficial da União, Brasília, DF, 26 jun. 2014.

BRASIL. Portaria no 892, de 17 de dezembro de 2013. Acreditação de cursos no Sistema Arcu-Sul. Diário Oficial da União, Brasília, DF, 18 set. $2013 \mathrm{a}$. 
BRASIL. Câmara dos Deputados. Projeto de Lei (PL) 4372/2012c. Cria o Instituto Nacional de Supervisão e Avaliação da Educação Superior INSAES, e dá outras providências. Disponível em: https://www.camara.leg. br/proposicoesWeb/fichadetramitacao?idProposicao $=554202$ Acesso em: 2 maio 2020.

BRASIL. Ministério da Educação. Comissão Especial de Avaliação da Educação Superior. Sistema Nacional de Avaliação da Educação Superior (Sinaes): Bases para uma nova proposta de avaliação da Educação Superior. Brasília, DF, 2004a.

BRASIL. Ministério da Educação. Portaria n ${ }^{\circ}$ 934, de 28 de maio de 1998. Institui o Exame Nacional do Ensino Médio - ENEM, como procedimento de avaliação do desempenho do aluno. Diário Oficial da União, Brasília, DF, 1 jun. 1998.

BRASIL. Ministério da Educação. Portaria nº 651, de 24 de julho de 2013. Institui a Matriz de Orçamento de Outros Custeios e Capital - Matriz OCC. Diário Oficial da União, Brasília, DF, 26 jul. 2013b.

BRASIL. Senado Federal. Constituição da República Federativa do Brasil - 1988: texto constitucional promulgado em 5 de outubro de 1988, com as alterações determinadas pelas Emendas Constitucionais de Revisão nos 1 a 6/94, pelas Emendas Constitucionais nos 1/92 a 91/2016 e pelo Decreto Legislativo no 186/2008. Brasília, DF, 2016.

BRESSER PEREIRA, L. C. B. Da administração pública burocrática à gerencial. Revista do Serviço Público, Brasília, DF, v. 120, n. 1, p. 7-40, 1996. https://doi.org/10.21874/rsp.v47i1.702

CAPANO, G. Government continues to do its job. A comparative study of governance shifts in the higher education sector. Public Administration, [s. 1.], v. 89, n. 4, p. 1622-1642, Dec. 2011. https://doi.org/10.1111/j.1467-9299.2011.01936.x

CAPANO, G. Policy design spaces in reforming governance in higher education: the dynamics in Italy and the Netherlands. Higher Education, [s. 1.], v. 75, n. 4, p. 675-694, Apr. 2018. https://doi.org/10.1007/s10734-017-0158-5

CORBUCCI, P. R.; KUBOTA, L. C.; MEIRA, A. P. B. Evolução da Educação Superior Privada no Brasil: da reforma universitária de 1968 à década de 2010. Radar, Brasília, DF, v. 46, p. 6, ago. 2016. https://doi.org/10.13140/RG.2.2.22695.96160 
DIAS SOBRINHO, J. Avaliação e transformações da educação superior brasileira (1995-2009): do Provão ao Sinaes. Avaliação: Revista da Avaliação da Educação Superior, Campinas, v. 15, n. 1, p. 195-224, 2010. https://doi.org/10.1590/S1414-40772010000100011

FERNANDES, R. et al. Avaliação de cursos na educação superior: a função e a mecânica do conceito preliminar de curso. Brasília, DF:

Instituto Nacional de Estudos e Pesquisas Educacionais Anísio Teixeira, 2009. (Textos para Discussão, v. 32).

HEIKKILA, T; GERLAK, A. K. Building a conceptual approach to collective learning: lessons for public policy scholars. The Policy Studies Journal, [s. 1..], v. 41, n. 3, p. 484-512, Aug. 2013. https://doi.org/10.1111/psj.12026

HONG, M. Public university governance in China and Australia: a comparative study. Higher Education, [s. 1.], v. 76, p. 717-733, oct. 2018. https://doi.org/10.1007/s10734-018-0234-5

INSTITUTO NACIONAL DE ESTUDOS E PESQUISAS EDUCACIONAIS ANÍSIO TEIXEIRA - INEP. Relatório do $3^{\circ}$ Ciclo de Monitoramento das Metas do Plano Nacional de Educação 2020. Brasília, DF, 2020.

INSTITUTO NACIONAL DE ESTUDOS E PESQUISAS EDUCACIONAIS ANÍSIO TEIXEIRA - INEP. Resultados do CPC 2015. Brasília, DF, 2016. Disponível em: http://portal.inep.gov.br/web/guest/educacao-superior/ indicadores-de-qualidade/resultados. Acesso em: 31 ago. 2020.

INSTITUTO NACIONAL DE ESTUDOS E PESQUISAS EDUCACIONAIS ANÍSIO TEIXEIRA - INEP. Resultados do CPC 2016. Brasília, DF, 2017. Disponível em: http://portal.inep.gov.br/web/guest/educacao-superior/ indicadores-de-qualidade/resultados. Acesso em: 31 ago. 2020.

INSTITUTO NACIONAL DE ESTUDOS E PESQUISAS EDUCACIONAIS ANÍSIO TEIXEIRA - INEP. Resultados do CPC 2017. Brasília, DF, 2018a. Disponível em: http://portal.inep.gov.br/web/guest/educacao-superior/ indicadores-de-qualidade/resultados. Acesso em: 31 ago. 2020.

INSTITUTO NACIONAL DE ESTUDOS E PESQUISAS EDUCACIONAIS ANÍSIO TEIXEIRA - INEP. Sinopse estatística da educação superior 1997. Brasília, DF, 1998. Disponível em: http://portal.inep.gov.br/web/guest/ sinopses-estatisticas-da-educacao-superior. Acesso em: 31 ago. 2020. 
INSTITUTO NACIONAL DE ESTUDOS E PESQUISAS EDUCACIONAIS ANÍSIO TEIXEIRA - INEP. Sinopse estatística da educação superior 2007. Brasília, 2008. Disponível em: http://portal.inep.gov.br/web/guest/sinopsesestatisticas-da-educacao-superior. Acesso em: 31 ago. 2020.

INSTITUTO NACIONAL DE ESTUDOS E PESQUISAS EDUCACIONAIS ANÍSIO TEIXEIRA - INEP. Sinopse estatística do Exame Nacional do Ensino Médio 2017. Brasília, 2018b. Disponível em: http://portal.inep.gov.br/ web/guest/sinopses-estatisticas-do-enem. Acesso em: 31 ago. 2020.

INSTITUTO NACIONAL DE ESTUDOS E PESQUISAS EDUCACIONAIS ANÍSIO TEIXEIRA - INEP. Sinopse estatística da educação superior 2017. Brasília, 2018. Disponível em: http://portal.inep.gov.br/web/guest/sinopsesestatisticas-da-educacao-superior. Acesso em: 31 ago. 2020.

INSTITUTO NACIONAL DE ESTUDOS E PESQUISAS EDUCACIONAIS ANÍSIO TEIXEIRA - INEP. Diretoria de Avaliação da Educação Superior. Análise do documento "Repensar a garantia da qualidade da Educação Superior no Brasil": Brasília, DF, 2019. Disponível em http://download.inep.gov.br/acoes_ internacionais/ocde/Consideracoes_OCDE_122018.pdf. Acesso em: 30 abr de 2020.

JENKINS-SMITH, H. C. et al. The advocacy coalition framework: an overview of the research program. In: WEIBLE, C. M.; SABATIER, P. A. (eds.), Theories of the Policy process. 4. ed. New York: Routledge, 2018. p. 135-171.

JENKINS-SMITH, H. C. et al. The advocacy coalition framework: foundations, evolutions and ongoing research. In: SABATIER, P. A.; WEIBLE, C. M. (eds.). Theories of the policy Process. 3. ed. Boulder: Westview, 2014. p. 183-223.

LACERDA, L. L. V.; FERRI, C.; DUARTE, B. K. C. SINAES: avaliação, accountability e desempenho. Avaliação: Revista da Avaliação da Educação Superior, Campinas, v. 21, n. 3, p. 975-992, ago./nov. 2016. https://doi.org/10.1590/S1414-40772016000300015

LEVY, D. C. Global private higher education: an empirical profile of its size and geographical shape. Higher Education, [s. 1.], v. 76, p. 701-715, Oct. 2018. https://doi.org/10.1007/s10734-018-0233-6

LIMA JUNIOR, P. et al. Taxas longitudinais de retenção e evasão: uma metodologia para estudo da trajetória dos estudantes na Educação Superior. Ensaio: Avaliação e Políticas Públicas em Educação, Rio de Janeiro, v. 27, n. 102, p. 157-178, jan./mar. 2019. https://doi.org/10.1590/s0104-40362018002701431 
MAHONEY, J.; THELEN, K. A theory of gradual institutional change. In: MAHONEY, J.; THELEN, K. (eds.). Explaining institutional change: ambiguity, agency and power. New York: Cambridge University Press, 2010. p. 1-37.

MERCOSUL. Conselho do Mercado Comum. Decisão n ${ }^{\circ}$ 17, de 30 de junho de 2008. Acordo sobre a criação e a implementação de um Sistema de Credenciamento de cursos de graduação para o reconhecimento regional da qualidade acadêmica dos respectivos diplomas no Mercosul e Estados associados. San Miguel de Tucumán, 2008. Disponível em: http://portal.mec.gov.br/dmdocuments/dec_017_conae.pdf. Acesso em: 30 abr. 2020.

OECD. Enrolment rate in secondary and tertiary education. Paris, 2020. Disponível em: https://data.oecd.org/students/enrolment-rate-in-secondaryand-tertiary-education.htm. Acesso em: 30 abr. 2020.

OECD. Rethinking quality assurance for higher education in Brazil. Paris, 2018. (Review of National Polivies for Education)

OSBORNE, S. P. The new public governance? Public Management Review, [s. 1.], v. 8, n. 3, p. 377-387, 2006. https://doi.org/10.1080/14719030600853022

PIRES, M. Alguns comentários a respeito das reformas recentes no FIES e os desafios atuais. Radar, Brasília, DF, n. 58, dez. 2018.

RED IBEROAMERICANA PARA EL ASEGURAMIENTO DE LA CALIDAD EN LA EDUCACIÓN SUPERIOR - RIACES. Mapa interativo: miembros. México, DC, 2020. Disponível em: http://riaces.org/miembrosmapa-interactivo/. Acesso em: 31 ago. 2020.

SANTOS, M. G.; LEITE, D. Rede regionais para acreditação e avaliação da qualidade da educação superior. Ensaio: Avaliação e Políticas Públicas em Educação, Rio de Janeiro, v. 27, n. 102, p. 108-128, jan./mar. 2019. https://doi.org/10.1590/s0104-40362018002701357

VERHINE, R. E.; DANTAS, L. M. V.; SOARES, J. F. Do Provão ao ENADE: uma análise comparativa dos exames nacionais utilizados no ensino superior brasileiro. Ensaio: Avaliação e Políticas Públicas em Educação, Rio de Janeiro, v. 14, n. 52, p. 291-309, jul./set. 2006. https://doi.org/10.1590/S0104-40362006000300002 


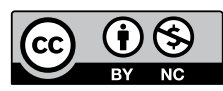

\section{Informações sobre os autores}

Janaina Ma: Doutoranda em Administração pela Universidade de Brasília. Pesquisadoratecnologista do Instituto Nacional de Estudos e Pesquisas Educacionais Anísio Teixeira. Contato: janainafma@gmail.com

iD https://orcid.org/0000-0003-3646-3720

Diego Mota Vieira: Doutor em Administração pela Universidade de Brasília. Professor vinculado ao Programa de Pós-Graduação em Administração da Universidade de Brasília. Líder do Grupo de Pesquisa em Governo e Políticas Públicas. Contato: diego1mv@yahoo.com.br

(iD) https://orcid.org/0000-0003-1275-1648 